\title{
Argumentation as Critically Oriented Pedagogical Dialogue
}

\author{
Chrysi RAPANTA
}

Reasoning and Argumentation Lab

Institute of Philosophy

Universidade Nova de Lisboa (IFILNOVA)

Lisbon, Portugal

crapanta@fcsh.unl.pt

\begin{abstract}
Argumentation in educational contexts has been proposed as a dialogic practice that stimulates and promotes students' critical thinking. However, the way critical thinking relates to argumentation is still not clear in the literature. This essay proposes the exploration of the concept of criticality, as manifested in students' and teachers' contributions within argumentative interactions, as the basis for the redefinition of "pedagogical dialogue" as a dialogue oriented towards critical argumentation. The main characteristics of this type of dialogue are described, shedding light on the connection between argumentation and critical thinking. These characteristics are illustrated through examples drawn from classroom interactions.
\end{abstract}

Résumé: L'argumentation dans les contextes éducatifs a été proposée comme une pratique dialogique qui stimule et favorise la pensée critique des étudiants. Cependant, la relation entre la pensée critique et l'argumentation n'est pas encore claire dans la littérature. Cet essai propose d'explorer le concept de la pensée critique, tel qu'il ressort des interactions argumentatives des élèves et des enseignants, et d'employer cette exploration comme base de la redéfinition du «dialogue pédagogique» en tant que dialogue orienté vers une argumentation critique. On décrit les principales caractéristiques de ce type de dialogue, et on met en lumière le lien qui existe entre l'argumentation et la pensée critique. Ces caractéristiques sont illustrées par des exemples tirés d'interactions en classe

Keywords: argumentation; critical thinking; dialogue; pedagogy

(C) Chrysi Rapanta. Informal Logic, Vol. 39, No. 1 (2019), pp. 1-31 


\section{Introduction}

Argumentation in educational contexts has been proposed as a dialogic practice that stimulates and promotes students' critical thinking (Kuhn 1999; Schwarz and Baker 2016). Recently, Kuhn and her colleagues have shown that argumentation is a pathway to the development of critical thinking skills manifested in written discourse (Kuhn, Hemberger, and Khait 2016; Hemberger et al. 2017). Critical thinking is also manifested within the oral practice of argumentation when students ask critical questions (Mayweg-Paus, E. Thiebach and Jucks 2016), engage transactively with each other (Felton and Kuhn 2001), and critically use evidence (Berland and Reiser 2009). These findings highlight the connection between argumentation and critical thinking; however, they also invite reflection on what critical thinking actually refers to. More specifically, it is unclear whether critical thinking is something linked to the practice of argumentation and manifested simultaneously therewith, or it is a pre-requisite of the latter, or an outcome of a "good" argumentation dialogue in the classroom.

The question of quality of argumentation dialogue is crucial in general, and also in educational contexts in particular (Keefer, Zeitz, and Resnick 2000). Scholars who favour adopting dialogue-based pedagogies have placed emphasis on authentic classroom discussions (Soter et al. 2008; Hadjioannou and Townsend 2015). These have, thus far, been defined in various ways and levels of assessment: (a) as teachers' dialogue acts that are more "authentic" than others, such as "authentic" versus knowledge-testing questions (Nystrand 2006); (b) as classroom dialogue sequences that do not follow the traditionally authoritative, teacher-centred Inquiry-Response-Evaluation pattern (Mehan 1979), but they are more open to inviting students' contributions (Wells and Arauz 2006) and/or increasing the discourse space (Boyd and Markarian 2011); and (c) as discussions (talks) as a whole, with disputational and cumulative types being less authentic than the so-called "exploratory talk" (Mercer, Wegerif, and Dawes 1999), which was proposed as "a way of using language effectively for joint, explicit, collabora-

(C) Chrysi Rapanta. Informal Logic, Vol. 39, No. 1 (2019), pp. 1-31 
tive reasoning" (ibid, p. 97). Substantial research from different cultures worldwide confirms that such authentic discussions are rare in the classrooms (Mercer, et al.1999; Hadjioannou 2007; Alexander 2005). Given their importance for the development of a critical (thinking) stance, both in students and in teachers (Soter et al. 2008; Boyd and Markarian 2011), many scholars have proposed ways to scaffold those discussions. The use of argumentation as a tool for guiding authentic teacher-students' dialogic interactions has thus far only been implicit, with some rare exceptions from science (e.g., Venville and Dawson 2010; McNeill et al. 2016), and with scholars' main focus on peer-topeer argumentation (e.g., Evagorou and Osborne 2013).

In this essay I propose argumentation as an explicitly dialogic practice able to promote criticality as manifested in student's contributions within a particular type of classroom interaction henceforth referred to as pedagogical dialogue. To do so, I will first define pedagogical dialogue to meet some "standards" (to avoid any notion of normativity, I will henceforth use the word "premises") of dialogical pedagogy. Then I will do the same for the concept of criticality. For the first definition, I will rely on key literature from Critical thinking and Informal logic, while for the latter I will draw on the field of Argumentation and Education. After this initial definition of the key concepts treated in the essay, I will present a framework for argumentation as a Critically Oriented Pedagogical Dialogue, which will focus on the critical aspects of students' and teacher's contributions.

\section{Towards defining "pedagogical dialogue"}

Skidmore (2006), in an effort to distinguish between dialogues that are inspired by a dialogical pedagogy and others that are not, uses the term pedagogical dialogue to refer to dialogues "in which someone who knows the truth instructs someone who is in error" and which are therefore "characterised by a tendency towards the use of authoritative discourse on the part of the teacher" (p. 293). A similar approach is taken by Walton (1998), who classifies pedagogical dialogue as part of his "information- 
seeking" dialogue, because, as he maintains, it "shares some common properties with expert consultation" (p. 236). However, Walton's view of pedagogical dialogue is somewhat different than Skidmore's, as it forms part of an argumentation dialogue; therefore, the types of arguments that emerge therein are crucial for defining whether it is more "authoritative" in the sense of didactic, or more persuasive in the sense of dialectical. Its characterization largely depends on whether the dialogue satisfies some main dialogical pedagogy ${ }^{1}$ premises, as the ones explained below.

The first premise is mainly evident in the work of Freire (1970), and it concerns the idea of co-intentional education. Under this perspective, teachers and students are both subjects and participants in the educational reality. As such, they coparticipate "not only in the task of unveiling that reality and thereby coming to know it critically, but in the task of recreating that knowledge" (p. 51). In other words, the starting point and result of a dialogical pedagogy should be the common participation and commitment of the two main stakeholders in the enterprise of learning, namely the teachers and the students. Such co-intention may be manifested in different ways when it comes to teacher-student dialogue, for example: students initiating a dialogue sequence, shifting the dialogue goal from one type to another, or contributing constructively to the fulfillment of the shared dialogue and epistemic goals.

However, the passage from the active participation in dialogue to the creation and transformation of knowledge (i.e., the epistemic level of dialogue) is not automatic. The mutually constitutive relationship between the individuals and the society, which is implied in the dialogicality of relations and concepts

\footnotetext{
1 The use of the term "dialogical pedagogy", perceived in its broader sense of a pedagogy aiming at dialogicality, rather than "dialogic pedagogy", referring to a concrete philosophical framework of dialogue mainly inspired by Mikhail Bakhtin (Matusov 2009) is intentional.
} 
taught within a constructive classroom environment or activity system, is the basis of what is conceived as a community of practice (Lave and Wenger 1991). Communities of practice (CoPs) are "groups of people who share a concern, a set of problems, or passion about a topic, and who deepen their knowledge and expertise in this area by interacting on an ongoing basis" (Wenger, McDermott, and Snyder 2002, p. 4). Building CoPs in a classroom, or better said, transforming a classroom into a $\mathrm{CoP}$, implies that intention is continuously framed and re-framed so that the common goal of learning takes place. This places students as participants in the production of their own knowledge (Skidmore 2006), and not as mere consumers of the knowledge given by the teacher, rendering shared epistemic agency a second important premise of a dialogical pedagogy.

The last premise, strongly connected with the previous one, reflects the idea about power and its use in an environment that promotes knowledge, understanding, and growth. Should teachers act as authorities or is their role "reduced" to one of supporting others in their process of development and learning, particularly with less-knowledgeable students? Reality should not be either one or the other. Objectively, teachers have more knowledge than the students or, better said, they are more often in the "position to know" than their students; however, such a position should not be associated to an instrument of power exercised against student's talk, ideas, or the right to be mistaken. Power in the sense of teacher's authority in the classroom "must be relative to doing something, and to the fact that things which most need to be done are things which involve one's relationships with others" (Dewey 1916; p.127). It is the power embedded in discourse and/or action and not pre-established on the basis of some type of authority that forms a third premise of a dialogical pedagogy.

In the view I develop in this paper, pedagogical dialogue is not and should not be merely authoritative, but it should embrace and manifest some key dialogical pedagogy premises, such as the ones described above. I will further claim that the manifestation of those premises, and therefore the fulfillment of 
pedagogical dialogue, is possible through the application of a main identifier of argumentation dialogue, namely criticality.

\section{Towards defining "criticality"}

Critical thinking (CT) is one of the most ill-defined terms in the field of Philosophy of Education. Currently there are more than ten scientific publications with the title, "Thinking critically about critical thinking," which makes us reflect on the value of being meta-critical regarding the definition and use of the concept. Having this in mind, this section will not aim at a definition of CT, rather it will focus on those ideas that will assist in the definition of "criticality" and its further use as a functional element of pedagogical dialogue.

The relation between critical thinking and argumentation as an educational practice is rooted in the relation between critical thinking and informal reasoning. For Siegel (1985), critical thinking and informal reasoning are interchangeable terms. More precisely, Siegel justifies his view of "critical thinking and/or informal logic as educational desiderata," and he further makes the point that "the important question is not, "Is there a generalized skill of critical thinking?", rather, "How does critical thinking manifest itself?" (p. 75). Siegel's answer is that "reasons can be both subject-specific and general" (ibid). Johnson and Blair's (1991) answer is: "in reasons (i.e., arguments) [which] are offered for and against alternative solutions" (p. 134). For Walton (1989), critical thinking is mainly manifested in the ability to look at both sides of an argument, which is fulfilled through a dialogical view of argument as explained below.

It is worth noting that among Informal logicians, such as Siegel, Johnson, Blair, and Walton, the discussion about critical thinking does not involve a discussion about critical thinking skills. Therefore, within informal logic, which is the philosophical field closer to the recent field of Argumentation and Education, it would not make sense to talk about critical thinking as an outcome of informal reasoning or argumentation practice. If it is 
not an outcome, then what is it? A disposition? And in case it is, is it a disposition towards what? The ideas presented below can help define a dispositional approach to $\mathrm{CT}$, the basis on which criticality will be defined.

First, "critical thinking is a self-adjusting process of judging what to believe or what to do in a given context" (Faccione 2000, p. 65). Second, CT skills are different than dispositions towards CT. As Faccione (2000) concludes, "being skilled does not assure one is disposed to use CT. And, being disposed toward CT does not assure that one is skilled" (p. 81). Third, dispositions towards CT refer to how willing a person is to apply critical thinking in certain situations. This willingness is strongly connected with epistemic values and goals (Weinstein 1990). In education, the majority of actions manifesting a lack of CT result from heuristic thinking and a lack of cognitive effort rather than the ability to analyze or synthesize. This renders CT closer to a dispositional approach (Krupat et al. 2011).

Treating CT as a disposition and not as a skill is also compatible with a critical view against CT tests, which were proposed as way to assess how critical one's thinking is. In his critique to the tests used to assess critical thinking as a skill, Ennis (1984) described a list of problems concerning the content of five of the most used tests in the US. One of the problems relates to assessment of the skill of induction, as performed by these tests, which does not entail the different levels of people's sophistication that might lead them to different levels of endorsement to a conclusion. As Ennis (1984) observes, some answers to such problems are found in the suggestions given by McPeck (1981) in his book, Critical Thinking and Education. Among other things, McPeck (1981) suggests a) that the answer format permits more than one justifiable answer, and b) that good answers are predicated based on the quality of justification given for a response (p. 149). In other words, CT is a disposition manifested by the type and quality of contributions and reasons that a person gives.

The plausibility of thinking, implied above, is also a central aspect of argumentative reasoning, which was initially con- 
ceived as equivalent to informal reasoning (see for example Means and Voss 1996). However, Johnson and Blair (1991) make a clear distinction between the two terms: "There are instances in which reasoning is informal but not argumentative (...) It seems to us that the crucial feature that makes informal reasoning what it is is the way in which it is conducted; that is, in natural language and without recourse to formal procedures or other formal mechanisms" (p. 134). Is then all everyday thinking considered informal reasoning? The answer is given by Perkins, Farady, and Bushey (1991) in the same volume: No, because everyday reasoning is not critical; it is typically biased and incomplete. This distinction between an argumentative/informal reasoning that is valid, therefore critical, and an argumentative/informal reasoning that is invalid, therefore uncritical, has been lately reversed by Walton (2010) and his innovative proposal of paraschemes as heuristic versions of the so-called argumentation schemes. In Walton's account, it is the reasoner's failure to consider or respond to a series of critical questions accompanying each scheme that renders his/her reasoning more heuristic, therefore more fallacious. In other words, it is CT, or aspects thereof, which defines the quality of argumentative reasoning.

Therefore, CT is not only a disposition, in the sense of a value, characterizing one's practice that guides him/her to be more attentive to the critical components of his/her reasoning (something similar to Aristotelian phronesis). It is also an aspect of argumentative reasoning, which will be henceforth referred to as criticality.

\section{Criticality of arguments-as-products}

Educational argumentation, i.e., the argumentation process that is aimed at educational goals, is aimed at least one of the two broadly defined pedagogical outcomes, known as "learning to argue" and "arguing to learn" (Muller-Mirza and PerretClermont 2009). In the former, the focus of implementing argumentation is the development of argumentation skills within the 
students, such as the construction of valid arguments, counterarguments, and rebuttals and the appropriate use of evidence to support them (Kuhn 2005). In the latter, the focus is on conceptual learning, sometimes also referred to as "conceptual change" (Asterhan and Schwarz 2009), resulting from the students' engagement in constructive argumentative interactions. In both uses of argumentation as a pedagogical practice, learning is intentional, and not an incidental outcome (Bereiter and Scardamalia 1989). As a result, the learning outcomes of argumentation are commonly manifested as reasoning structures within the dialogue, also known as arguments-as-products (Macagno 2016). The type of outcome of argumentative reasoning resulting from engaging in an argumentation practice depends on the type of learning goal pursued through it.

Learning is always related to knowledge; however, how knowledge is treated through an intentional learning practice, such as argumentation, may vary. Van Aalst (2009) claims that when it comes to learning-aimed discourses, at least three types are possible, namely: knowledge-sharing, knowledgeconstructing, and knowledge-creating. The first aims at the transmission and sharing of information without it being interpreted or evaluated (van Aalst 2009). An example of this type of discourse is the information-seeking argumentation dialogue, which, when applied in the classroom, resembles an Inquiry-Response-Evaluation (IRE) pattern (Mehan 1979), with the only difference that it may also be open to feedback from both students and the teacher. In the example presented in Table 1 , the teacher initiates the sequences (line 167) with a question addressed to everyone, which is answered by Student 2 (line 170), and then evaluated by the Teacher in line 171, with a further elaboration (re-formulation) of it in lines 171 and 173. The "learning talk" (Alexander 2005) is fulfilled in lines 174 and 175 , in which the same student makes his/her reasoning explicit, as a result of the discussion held before. 
Table 1. Example of an information-seeking dialogue started by the teacher ${ }^{2}$.

\begin{tabular}{|c|c|c|}
\hline$\overline{\text { Line }}$ & Sp. & Transcript \\
\hline$\overline{167}$ & Teacher & $\begin{array}{l}\text { Right, can you link mass, gravity, and weight } \\
\text { together for me? }\end{array}$ \\
\hline 168 & Stud1 & What? \\
\hline 169 & Teacher & $\begin{array}{l}\text { Can you link mass gravity and weight together for } \\
\text { me? }\end{array}$ \\
\hline 170 & Stud2 & $\begin{array}{l}\text { Yes. The weight is the; no wait...the mass is the } \\
\text { matter, is the matter of an object, the gravity pulls } \\
\text { the mass down that creates the weight. }\end{array}$ \\
\hline 171 & Teacher & $\begin{array}{l}\text { Brilliant. So, mass is affected by gravity, and that } \\
\text { creates weight. }\end{array}$ \\
\hline 172 & Stud3 & Yeah. \\
\hline 173 & Teacher & $\begin{array}{l}\text { And the more gravity there is, the more weight will } \\
\text { be produced. } \\
\text { OK. So use those ideas, use those ideas, yeah? }\end{array}$ \\
\hline 174 & Stud2 & Mass times gravity is weight. \\
\hline 175 & Teacher & $\begin{array}{l}\text { There you go. It's a mathematical way of express- } \\
\text { ing the same thing. }\end{array}$ \\
\hline
\end{tabular}

In the type of dialogue such as the one presented above, contributions tend to be concrete answers to concrete questions, without the possibility of multiple perspectives and justifiable answers. This possibility is an essential aspect of critical thinking, as explained in the previous section. Therefore, students' contributions stay at an inference level (lines 170, 174), without becoming arguments, namely in this case, genuine contributions to the knowledge-sharing process.

\footnotetext{
2 The examples on Tables 1, 2, and 3 are from another paper (Rapanta and Christodoulou 2019).

(C) Chrysi Rapanta. Informal Logic, Vol. 39, No. 1 (2019), pp. 1-31
} 
In the case of knowledge-constructing discourses, they aim at producing "deeper" knowledge, but what this means and how it may be achieved varies with different educational approaches (van Aalst 2009). When a problem is given to students, argumentation dialogue as a knowledge-constructing discourse resembles an inquiry dialogue; in contrast, when students come up with a problem themselves, it is similar to a discovery dialogue. In both cases, there must be a problem, i.e., an issue or a doubt, that must be resolved. Participants, i.e., teacher and students, contribute to its resolution through different knowledgeconstructing acts, such as explaining, interpreting, evaluating, summarizing, re-constructing new information, and/or creating new concepts (van Aalst 2009). Within this knowledgeconstruction process, aimed at the search of a solution or of a problem, criticality depends on the nature of solution or problem proposals. Table 2 shows an example of an inquiry dialogue initiated by the teacher.

Table 2. Example of an inquiry dialogue started by the teacher.

\begin{tabular}{|c|c|c|}
\hline Line & Speaker & Transcript \\
\hline 183 & Teacher & Did you argue it out? \\
\hline 184 & Stud1 & Yeah. \\
\hline 185 & Stud2 & $\begin{array}{l}\text { Yeah but, Miss, is it } 100 \% \text { accurate yeah? } \\
\text { When you have cells removed, could it affect } \\
\text { their future or whatever? }\end{array}$ \\
\hline 186 & Teacher & Possibly, we don't know. \\
\hline 187 & Stud3 & But it said on the last video that, \\
\hline 188 & Stud2 & She said that on the video, \\
\hline 189 & Stud3 & It said on the video that $100 \%$ not affected. \\
\hline 190 & Teacher & $\begin{array}{l}\text { Yeah, so far everything they have carried on so } \\
\text { far it hasn't affected them but, }\end{array}$ \\
\hline
\end{tabular}


191 Stud2 It's inaccurate.

192 Stud3 She said they are affected and I said that it hardly do anything, it won't hurt really.

193 Teacher Yeah, you kind of, the evidence so far have shown that it's fine, it doesn't hurt them, but we never know, things can always go wrong.

194 Stud3 So is both right?

195 Teacher Yeah, kind of.

In the example above, Students 2 and 3 are having a disagreement on whether the cells (in the case of cystic fibrosis) will be affected by their removal. Students' moves 189,191 , and 192 may be considered as arguments-contributions to the resolution of the issue. However, it is still unclear whether these arguments are critical or not, as they are incomplete from an argumentative reasoning point of view: Students 2 and 3 refer to isolated pieces of evidence (i.e., a video they saw in the class), but they fail to integrate such evidence in their own arguments. Moreover, for arguments to be authentic, and thus critical, the inquiry process needs to be authentic, and meaning needs to be constructed internally as part of the learner's own initiative. This requirement is partially fulfilled in the example above, as in line 185, Student 2 makes the doubt (issue) explicit. However, a critical inquiry also implies the learner's engagement in examining his/her own prior knowledge, and how it changes through the "acquisition of convictions that are more reliable" (Lipman 2003). In the case above, the students' main worry concerns the correctness of their contributions (line 194) and not the analysis of the reliability of their perspectives and the reasons thereof. Thus, students' contributions in the example of Table 2 do not manifest criticality, as there is no evidence of self-examination regarding the construction of new knowledge (here "new" refers to the person, and not the epistemological community). 
Finally, knowledge-creation discourse is the only one of the three types of discourse that tends to be more argumentative (van Aalst 2009), as it resembles the discourse of a community of practice, which was introduced previously in the essay as a premise of dialogical pedagogy. In argumentation dialogue terms, this means that: (a) all contributions in the discourse should resemble contributions of people sharing their concerns, interests, and knowledge about the topic under discussion; (b) these contributions must be acceptable by the corresponding knowledge community; and (c) what makes a contribution more acceptable than another is the use of acceptable evidence within the given community. Through learners' participation in classrooms transformed into this type of epistemological communities, their discourse becomes more argumentative, and therefore more reflexive and sophisticated (Duschl and Osborne 2002). Table 3 shows an example of such a discourse obtained through a type of dialogue, resembling Walton's (1998) persuasion dialogue.

Table 3. Example of a persuasion dialogue started by the teacher.

\begin{tabular}{|c|c|c|}
\hline Line & Speaker & Transcript \\
\hline 153 & Teacher & $\begin{array}{l}\text { Right, so you're for, and you're against. OK. So } \\
\text { what S1 just said to you? }\end{array}$ \\
\hline 154 & Stud2 & Nothing. She's not to start. \\
\hline 155 & Teacher & Right, so who's starting? \\
\hline 156 & Stud2\&3 & Us. \\
\hline 157 & Stud1 & They are going with against. \\
\hline 158 & Teacher & Alright then, go on, so why is it wrong? \\
\hline 159 & Stud2 & No, we're not talking about... \\
\hline 160 & Stud3 & $\begin{array}{l}\text { It is wrong because that would mean that the } \\
\text { doctors can cause defects to the child that }\end{array}$ \\
\hline
\end{tabular}


doesn't even have cystic fibrosis.

161 Teacher Yeah, so you,

162 Stud2 Because they are missing embryos from,

163 Teacher Cells. Yeah, so they are taking cells from the embryo, so they don't know what effect that could have later on in life.

164 Teacher How are you going to reply to that?

165 Stud4 Ehm,

166 Stud3 They can't.

167 Stud5 No, because they won't know unless they try. So like even if the kid has one little batch of skin that it's like different, it's better than having cystic fibrosis.

168 Teacher Good.

The students' contributions seen in Table 3 can be considered evidence-based arguments, as considerable efforts are made in applying argumentation's epistemic standards of evidence interpretation (lines 161-162) and assessment (line 167). However, we still cannot talk about authentic contributions, as one important critical argumentation skill fails to be manifested, which is the skill of antilogos. Antilogos refers to the ability to critically evaluate whether specific information can support different claims (Glassner and Schwarz 2007). The lack of manifestation of this ability results in two of the main critical thinking flaws defined as "my-side" bias and "makes-sense" epistemology (Perkins et al. 1991). On the contrary, when antilogos is present, the consideration of the other side is manifested in the quality of one's own contributions, in what is called a two-sided, balanced, or dialogical argument (Polo, Lund, Plantin, and Niccolai 2016). None of the two complete arguments in the example of 
Table 3, i.e., Student's 3 argument in line 160 and Students' 5 argument in line 167, is a two-sided argument.

\section{Argumentation as critically oriented pedagogical dialogue}

According to Walton (2014), a type of dialogue is defined through its initial situation, the participants' individual goals, and the aim of the dialogue as a whole. In an inquiry dialogue, for example, the initial situation is described as a need to have proof, the goal of participants is to find and verify evidence, and the goal of the dialogue itself is to prove or disprove hypothesis. Similarly, in a discovery dialogue, the initial situation is the need to find an explanation, the participants' goal is to find and defend a hypothesis, while the dialogue goal is to choose the best hypothesis. What should the main characteristics of a pedagogical dialogue be?

The idea of a pedagogical dialogue proposed here is one in which: a) the initial situation is that of a critical inquiry and construction of knowledge; b) the goal of participants is to jointly elaborate the intention and contents of dialogue, and c) the goal of the dialogue is to embed participants' power in the use of evidence-based discourse. Under this view, any teacherstudents' interaction that is characterized by critical knowledge construction, joint elaboration, and the intentional use of argumentative, evidence-based discourse belongs to this type of dialogue defined here as Critically Oriented Pedagogical Dialogue (COPD). The criteria for defining this dialogue stem from some main premises of dialogical pedagogy, as explained earlier in the paper; therefore, they tend to be inclusive and interdisciplinary. In this sense, the use of the word "evidence" is broader than its use in scientific contexts, including any kind of support further given to render one's arguments more credible. In addition, not all three criteria of COPD described above need to be equally present for a dialogue, or an instance of dialogue, to be characterized as such. Although the criterion of the initial situation is a necessary condition for COPD to take place, participants' and dialogue goals' can be more or less fulfilled on 
basis of the manifested efforts in discourse. In this sense, my proposal of COPD is not normative but descriptive, as will be showcased below.

\section{Examples of COPD manifestations}

Sharing, by making both information and reasoning explicit, is the starting point for any type of authentic dialogue to take place. This sharing is usually manifested by freely exploring ideas and arguments in a format of talk usually referred to as "exploratory talk". Exploratory talk can either be initial, i.e., at an information-seeking level or more inquiry-related, for example when students are asked to explore variables to give answers to teacher-framed open questions. Examples of such questions are: 'What outcomes would you predict?' (in science) or 'Was decision x successful?' (in history). Students are invited to give their own accounts of why certain scientific phenomena take place, or why certain decisions were taken in a historical perspective, or what decision to take regarding a socio-scientific issue, for example.

Table 4 shows an example of an exploratory type of COPD, where students are introduced to a critical inquiry and they are invited to contribute using and drawing on their knowledge. Such knowledge is expressed with presenting different accounts of a phenomenon, which, in science, correspond to scientific explanations (Berland and Reiser 2009). The level of criticality is defined by the nature of these contributions being formed as justifiable arguments, rather than mere ideas spoken out. The example of Table 4 is more "critically oriented" than the example in Table 1, although both have an apparent IRE structure. The difference lies in (a) the type of issue, presented as a phenomenon to explore and understand (line 1) and not as a question to answer; (b) the engaged efforts for its resolution, which manifest signs of co-constructed explanations (lines 2-3, and 910); (c) and the search for best explanation, made explicit through teacher's "maieutic" questions (lines 6, 8, 11). 
Table 4. Example of COPD dialogue as an exploration of different theories (Physics, $9^{\text {th }}$ grade, the excerpt is from Scott, Mortimer, and Aguiar 2006, pp. 619-20).

1 Teacher Now, what happens to the thermometer when its temperature goes up? What's happening in the thermometer? Does some kind of change take place?

2 Stud3 I think so, because the mercury in the thermometer only goes up and down, expands or contracts according to the temperature. It expands 3

When the temperature is higher. It must have a heat change to go up and down.

3 Stud6 I think that the stuff in the thermometer is made of a material that doesn't take much heat to make it change. That's its property, and that's why it's used in a thermometer. It's sensitive to whatever's being measured.

4 Teacher A good thermometer mustn't take too much heat; otherwise it would lower the temperature of the object to be measured, OK?

5 Stud6 There is heat transfer, but the mercury doesn't take much. That's why it's used in thermometers, to measure the energy from the particles.

6 Teacher There is a small amount of energy [transferred to the thermometer/mercury] but if there was no energy, would it be possible for the mercury to expand?

7 Stud? No, I don't think it would.

8 Teacher And there was an expansion of the mercury, wasn't there?

9 Stud8 Any change in heat, due to its sensitivity, changes its temperature. When you get this thermometer and put it in the surroundings, then it's at $25^{\circ}$. When you put it in ice the temperature decreases so fast because the heat from the ice is higher and the mercury is sensitive to it and so it goes lower. 

10 Stud6 And I think that the energy of the mercury will be equal to that of the ice that is moving faster and will make the mercury go up or down.

11 Teacher Let's consider this situation you have mentioned. It was at 25 degrees, and then you put it in the ice, and then the temperature decreased. And you are saying that the ice, in this situation, has more heat than the thermometer? Is there any heat transfer in this case? What is the direction of this heat change; heat transfer in this case?

The example above shows that the focus of both the teacher and the students is on sharing knowledge, expressed as an inquiry or search for possible variables that explain what happens to the thermometer when it goes up. It also shows that teacher's questions open the space for critical inquiry, as they invite possible answers. Nonetheless, the students' explanations are not confronted; they are just put on the table as alternatives or possible answers to the main question asked by

the teacher. Therefore, the example can be considered as a minimal or initial manifestation of a COPD, one that focuses on the knowledge-sharing function of discourse.

If the excerpt above is an example of a knowledge-sharing argumentation dialogue, the example in Table 5 is a demonstration of what critical co-construction in pedagogical dialogue can look like, thus satisfying the second COPD criterion, the joint elaboration of the intentions and contents of a dialogue. For such co-construction to take place, another type of talk was proposed in the literature, known as accountable talk (Michaels, O' Connor, and Resnick 2008). According to these authors, accountability must be expressed towards: a) knowledge, b) standards of reasoning and c) the learning community. In other words, co-constructive talk can take place through warranted reasoning and knowledge. The use of reasons that satisfy epistemic, reasoning, and epistemological standards implies a certain degree of accountability from the participants. Although in exploratory talk students' accountability may not matter much,

(C) Chrysi Rapanta. Informal Logic, Vol. 39, No. 1 (2019), pp. 1-31 
since what matters is the process of exploring together. In accountable talk the students produce knowledge through interacting with each other and with the teacher, and therefore, they become accountable for the knowledge they create.

Table 5. Example of a COPD dialogue as a joint elaboration of knowledge (translated from the original language, Natural sciences, 9th grade; the excerpt is from a whole class debate on whether or not we should do sports in the open air).

1 Andrew Ok, the point is about the spaces ... in the closed spaces, there is more transmission of bacteria and viruses between people ... so, everyone gets sick if someone gets sick. In the exterior, there are also bacteria and viruses; this is why we can also get sick. But... there is more oxygen than an interior space, because the air... is always the same, and when we inhale and exhale, it is ... there is more carbon dioxide getting out ... and therefore the concentration of carbon dioxide in the space starts to increase and that of oxygen to decrease...

2 Laura One of the problems of doing sports in the open air is the solar exposition ... we have to carry ... if we are not protected, it can affect our skin, even when the sun is not ... even when it is cloudy ... [inaudible] (she goes on her reasoning mentioning also vitamin D).

3 Teacher And how is it that vitamin D relates to that? Explain!

4 Laura When ... if we are doing sports in the open air ... but being protected ... we can captivate the sun energy but not the vitamin D...

5 Teacher When we are wearing sun protection, can we absorb vitamin D? (addresses the question to the class)

6 choir Yes!

7 Teacher Do you agree with her? 
8 choir Noooo!

9 Teacher So, how is it?

10 Laura I may be mistaken, but when the vitamin D, it only gets absorbed, if we have...if we don't wear sun protection ... [ ]

11 Teacher It is not about being protected or not protected. It is ... when... when the sun... it projects on our skin, doesn't it? There is a substance, let's say, in our skin, called pro-vitamin D and the sun helps this substance to be transformed into vitamin D ... and so, go on with your reasoning... how is it now?

12 James Miss, but how is it that ... if we put on sun protection, we don't take in any vitamin D? If not, then it is bad to wear any protection ... shall I put the protection or take in vitamin D? It doesn't sound right; we have to have our sun protection on... (students laugh)

13 Teacher So? How can we solve this?

14 choir [inaudibe] (students talk simultaneously)

15 Andrew We can be outdoors during the hours that it is not as hot ... that is ... we cannot be at the sun between 10 in the morning and 4 in the afternoon.

The example in Table 5 is more critically oriented than the example in Table 2, although both aim at finding an answer to a problem. The main difference lies in the fact that in the example above, the COPD criterion of joint elaboration is manifested because critical inquiry is also present. This criticality is expressed with the counterarguments and rebuttals expressed by both the students and the teacher. There is still some evidence that the teacher is the main "owner of knowledge," as shown in her fifth contribution (line 11), in which she warrants the main argument on which students' contributions are judged as correct or not. However, as this dialogue is from a scientific context, it is expected that these types of warrants are given by the teacher, 
as they correspond to scientific laws that often do not form part of students' prior knowledge.

The following and last example of COPD is considered a knowledge-creation dialogue with persuasive discourse characteristics. Although it is common to encounter such types of dialogues in peer-to-peer collaborative deliberation dialogues (e.g., Felton, Garcia-Mila, and Gilabert 2009), it is difficult to identify them within teacher'-students' interaction. The main challenge for the teacher is to "abandon" his/her pre-defined authority and to search for a new type of "authority," embedded in evidence and arguments. In Table 6, there is an example of a COPD, in which the teacher allows a student to answer to another student's counterargument through a rebuttal, which she (the teacher) reinforces with an argument by analogy. The learning outcome is the creation of new knowledge, which is possible through the use of argumentative discourse.

Table 6. Example of a COPD dialogue as a way of embedding (teacher's) power in the use of argumentative discourse (translated from the original language, History, 9th grade; the excerpt follows a discussion about the characteristics of the Soviet communism).

$1 \quad$ Maria $\quad$ It doesn't make much sense, imagine a person who works more, will she receive the same as another person who works less? It doesn't make much sense...

2 Teacher We will not enter such a debate today, sorry but I have to conclude this... It doesn't make much sense, why? Say, Maria, why do you think it doesn't make much sense?

3 Teacher Who can measure that the work of one is superior to the work of the other? Who can measure the value of this work for the society?

4 Maria Same work, both of them work in the fields, one person works for 8 hours, the other works for 4 . How do they decide, I don't understand how they decide on equal wealth if there are people who work more...

5 Teacher Because it is that, it starts from the principle that

(C) Chrysi Rapanta. Informal Logic, Vol. 39, No. 1 (2019), pp. 1-31 


\begin{tabular}{|c|c|c|}
\hline & & $\begin{array}{l}\text { in this ultimate state of society, as people do not } \\
\text { choose anymore the profession they operate... }\end{array}$ \\
\hline 6 & Teresa & They do what they want. \\
\hline 7 & Teacher & Exactly. Go on, Teresa, you were saying well. \\
\hline 8 & Teresa & $\begin{array}{l}\text { People often choose a job because they earn more, } \\
\text { but there (she means the Soviet society) given that } \\
\text { everyone earns the same, they are happy to do it, } \\
\text { they will do it. }\end{array}$ \\
\hline 9 & Teacher & $\begin{array}{l}\text { They get pleasure in performing that job; they will } \\
\text { do it... And I will also add to that with a response, } \\
\text { we cannot waste much time on those conversa- } \\
\text { tions, but I will reply to you with an article that I } \\
\text { read last year in the Expresso. }\end{array}$ \\
\hline 10 & Teacher & $\begin{array}{l}\text { You, guys, know what is on fashion these days, } \\
\text { you also go to a congress next week, don't you? } \\
\text { About start-ups, have you heard talking about } \\
\text { that? }\end{array}$ \\
\hline 11 & Choir & Yes. \\
\hline 12 & Teacher & $\begin{array}{l}\text { There are colleagues of yours from the secondary } \\
\text { who are going there, right. }\end{array}$ \\
\hline 13 & Teacher & $\begin{array}{l}\text { There was this start up, the name of which I don't } \\
\text { recall right now, and also, I don't remember the } \\
\text { name of the guy but it's not important. What } \\
\text { matters is that he was working since two or three } \\
\text { years, he had already founded one of these high- } \\
\text { technology industries, and he decided, he was } \\
\text { young, he must be in his thirties, and he decided } \\
\text { that in his company everyone from himself, who } \\
\text { was on the top of the management, until the } \\
\text { doorman, everyone would receive the same salary. }\end{array}$ \\
\hline 14 & Teacher & $\begin{array}{l}\text { And some time later, this was some time ago; I } \\
\text { read again in the Expresso that this guy... that the } \\
\text { company works with the maximum productivity } \\
\text { and that there have not been any problems from } \\
\text { the fact that the doorman would receive the same } \\
\text { salary as the manager. It was around } 5000 \text { dollars } \\
\text { per month. }\end{array}$ \\
\hline
\end{tabular}

In several instances, we notice that the teacher struggles with her regulatory authority, i.e., to go on with the class, and she 
affirms that "those conversations" are something they "cannot waste much time on" (line 9). Although she continuously affirms that there is no time to enter a debate, which is a common truth in a middle-grades classroom, she further backs up the argument made by Teresa with an argument from analogy, a story of a successful businessman applying a norm like the wealth equality in the former Soviet system. Her disciplinary authority gets manifested through her argumentative discourse, and not through her pre-defined authority, as in a teachercentered, non-dialogic classroom environment. In addition, both the students and the teacher use certain types of argumentation schemes (Maria uses practical reasoning - line 4, whereas the teacher uses an argument from analogy - lines 13-14), establishing their role as part of a $\mathrm{CoP}$, in which everyone is assigned the responsibility of sharing reasoning and knowledge for the common goal.

The three examples above represent independent manifestations of COPD, with different learning outcomes: knowledgesharing, knowledge-constructing, and knowledge-creating. The goal was to show how COPD may be manifested in classroom everyday discourse as part of teacher-students interaction. On no account should these examples be considered ideal situations of dialogue, as this is not the objective. Argumentation as COPD is rather difficult to achieve, and its success depends on many factors, some of which relate to teachers' professional development and preparedness for such an adventure (Wilkinson et al. 2017).

\section{Discussion}

The theoretical definition of a critically oriented pedagogical dialogue (COPD) made in the present article is well combined with the empirical findings in the fields of both argumentation and critical thinking since these fields focus on the importance of explicit teaching and engagement in the process of reasoning for improvement effects to be evident among students (Erduran, Simon, and Osborne 2004; Marin and Halpern 2011; Venville 
and Dawson 2010; Zohar and Nemet 2002). The implementation of argumentation practice as a vehicle for the promotion of dialogical pedagogy in the classroom is a key element in this practice-based approach. Preparing teachers with the right tools for fostering inquiry, co-intention, and discourse-embedded power in argumentative dialogues with the students is the future direction of this research.

The focus on argumentation as the basis for pedagogical dialogue further helps avoid the use of CT as a self-defined term, which would cause confusion in educational practice regarding what and how to be assessed as critical. Nonetheless, not all types of argumentation taking place in educational contexts are manifestations of dialogic teaching (Alexander 2005). The example of persuasive COPD in Table 6 is doubtful in this respect. For dialogic teaching to take place, a connection with dialogue-promoting goals needs to be made explicit in teachers' efforts to increase students' agency and participation, for example through reducing their own. In the example of Table 6 , there is a contrast: on the one hand, the dialogue, as I showed, can be defined as "critically oriented" based on the criticality manifested both in teacher's and students' contributions, therefore, in arguments-as-products. Nonetheless, it can also be claimed that the dialogue is not critical from an argument-as-process point of view, as the teacher tends to close the space of dialogue down instead of opening it up (Wegerif 2007), as her last two contributions show. Further research in how argumentation may also be a useful tool for defining criticality at an argument-as-process level is necessary in this regard.

Another limitation, related to the previous one, may be the fact that this paper has only focused on the epistemic aspects of argumentation as a type of pedagogical dialogue. Recent research places increased attention on the role of emotions in the development and effect of argumentative discussions both in the classroom and in computer-supported collaborative learning environments (e.g., Polo et al. 2016). The strong connection between argumentation and emotions (Gilbert 2013), as manifested in discourse, provides more evidence towards the con- 
straints of a critical thinking approach to pedagogical dialogue, as $\mathrm{CT}$ focuses on rationality as the only standard of effective communication, leaving out other parameters, mainly of a socioemotional nature.

In conclusion, this essay contributed in our understanding of one aspect of the relation between argumentation and CT, the one manifested in the quality of arguments emerged within teacher-students interaction, and how this quality may reveal criticality of discourse, which is an essential aspect of dialogical pedagogy. Future research will shed light on how other aspects of discourse, related to argumentation dialogue as a process rather than the reasoning products within this process, may also be crucial in defining a pedagogical dialogue's potential towards critical thinking.

\section{References}

Aalst, Jan van. 2009. "Distinguishing Knowledge-Sharing, Knowledge-Construction, and Knowledge-Creation Discourses." International Journal of Computer-Supported Collaborative Learning 4 (3): 259-87. https://doi.org/10.1007/s11412-0099069-5.

Alexander, Robin. 2005. "Culture, Dialogue, and Learning: Notes on an Emerging Pedagogy." Keynote speech at the $10^{\text {th }}$ International Conference of the International Association for Cognitive Education and Psychology. Durham, UK.

Asterhan, Christa S. C, and Baruch B. Schwarz. 2009. "Argumentation and Explanation in Conceptual Change: Indications from Protocol Analyses of Peer-to-Peer Dialog." Cognitive $\quad$ Science 33 (3): $\quad 374-400$. https://doi.org/10.1111/j.1551-6709.2009.01017.x.

Bereiter, Carl, and Marlene Scardamalia. 1989. "Intentional Learning as a Goal of Instruction." In Knowing, Learning, and Instruction: Essays in Honor of Robert Glaser., edited by L. B. Resnick, 361-92. Hillsdale, NJ: Lawrence Erlbaum Associates.

Berland, Leema Kuhn, and Brian J. Reiser. 2009. "Making Sense of Argumentation and Explanation." Science Education 93 (1): 2655. https://doi.org/10.1002/sce.20286. 
Boyd, Maureen Patricia, and William C. Markarian. 2011. "Dialogic Teaching: Talk in Service of a Dialogic Stance." Language and Education 25 (6): 515-34. https://doi.org/10.1080/09500782.2011.597861.

Duschl, Richard, and Jonathan Osborne. 2002. "Supporting and Promoting Argumentation Discourse in Science Education." Studies in Science Education 38 (1): 39-72. https://doi.org/10.1080/03057260208560187.

Ennis, Robert H. 1984. "Problems in Testing Informal Logic, Critical Thinking, Reasoning Ability." Informal Logic 6 (1): 3-9. http://amr.uwindsor.ca/ojs/leddy/index.php/informal_logic/articl e/download/2717/2158.

Erduran, Sibel, Shirley Simon, and Jonathan Osborne. 2004. "TAPping into Argumentation: Developments in the Application of Toulmin's Argument Pattern for Studying Science Discourse." Science Education 88 (6): 915-33. https://doi.org/10.1002/sce.20012.

Evagorou, Maria, and Jonathan Osborne. 2013. "Exploring Young Students' Collaborative Argumentation within a Socioscientific Issue." Journal of Research in Science Teaching 50 (2): 209-37.

Faccione, Peter. 2000. "The Disposition toward Critical Thinking: Its Character, Measurement, and Relationship to Critical Thinking Skill." Informal Logic 20 (1): 61-84.

Felton, Mark, Merce Garcia-Mila, and Sandra Gilabert. 2009. "Deliberation versus Dispute: The Impact of Argumentative Discourse Goals on Learning and Reasoning in the Science Classroom." Informal Logic 29 (4): 417-46. http://ojs.uwindsor.ca/ojs/leddy/index.php/informal_logic/article/ view/2907.

Felton, Mark, and Deanna Kuhn. 2001. "The Development of Argumentive Discourse Skill." Discourse Processes 32 (2): 13553. https://doi.org/10.1207/S15326950DP3202\&3_03.

Freire, Paulo. 1970. Pedagogy of the Oppressed. New York: Continuum.

Gilbert, Michael. 2013. Co-Alescent Argumentation. New York: Routledge. 
Glassner, Amnon, and Baruch Schwarz. 2007. "What Stands and Develops between Creative and Critical Thinking? Argumentation?" Thinking Skills \& Creativity 2 (1): 10-18.

Hadjioannou, Xenia. 2007. "Bringing the Background to the Foreground: What Do Classroom Environments That Support Authentic Discussions Look Like?" American Educational Research Journal 44 (2): 370-99. https://doi.org/10.3102/0002831207302173.

Hadjioannou, Xenia, and Jane S. Townsend. 2015. "Examining Booktalks to Shed Light on Authentic Classroom Discussion." Classroom Discourse 6 (3): $198-220$. https://doi.org/10.1080/19463014.2015.1047876.

Hemberger, Laurie, Deanna Kuhn, Flora Matos, and Yuchen Shi. 2017. "A Dialogic Path to Evidence-Based Argumentive Writing." Journal of the Learning Sciences 26 (4): 575-607.

Johnson, Ralph, and Anthony Blair. 1991. "Contexts of Informal Reasoning: Commentary." In Informal Reasoning and Education, edited by James F. Voss, David N. Perkins, and John W. Segal, 131-50. Mahwah: Lawrence Erlbaum Associates.

Keefer, Matthew W., Colleen M. Zeitz, and Lauren B. Resnick. 2000. "Judging the Quality of Peer-Led Student Dialogues." Cognition and Instruction 18 (1): 53-81.

Krupat, Edward, Jared Sprague, Daniel Wolpaw, Paul Haidet, Dsvid Hatem, and Bridget O'Brien. 2011. "Thinking Critically about Critical Thinking: Ability, Disposition or Both?" Medical Education 45 (6): 625-35.

Kuhn, Deanna. 2005. Education for Thinking. Cambridge, Mass.: Harvard University Press.

Kuhn, Deanna, Laurie Hemberger, and Valerie Khait. 2016. "Tracing the Development of Argumentive Writing in a Discourse-Rich Context.” Written Communication 33 (1): 92121.

Lave, Jean, and Etienne Wenger. 1991. Situated Learning: Legitimate Peripheral Participation. New York: Cambridge University Press. 
Lipman, Matthew. 2003. Thinking in Education, 2nd Edition. Cambridge: Cambridge University Press.

Macagno, Fabrizio. 2016. "Argument Relevance and Structure. Assessing and Developing Students' Uses of Evidence." International Journal of Educational Research 79: 180-94.

Marin, Lisa M., and Diane F. Halpern. 2011. "Pedagogy for Developing Critical Thinking in Adolescents: Explicit Instruction Produces Greatest Gains." Thinking Skills and Creativity 6 (1). https://doi.org/10.1016/j.tsc.2010.08.002.

Matusov, Eugene. 2009. Journey into Dialogic Pedagogy. New York: Nova Science Publishers.

Mayweg-Paus, Elisabeth, Monica Thiebach, and Regina Jucks. 2016. "Let Me Critically Question This!-Insights from a Training Study on the Role of Questioning on Argumentative Discourse." International Journal of Educational Research 79: 195-210.

McNeill, Katherine, Maria Gonzalez-Howard, Rebecca KatshSinger, and Suzanna Loper. 2016. "Pedagogical Content Knowledge of Argumentation: Using Classroom Contexts to Assess High-Quality PCK Rather than Pseudoargumentation." Journal of Research in Science Teaching 53 (2): 261-90. https://doi.org/10.1002/tea.21252.

McPeck, John. 1981. Critical Thinking and Education. Oxford: Robertson.

Means, Mary L., and James F. Voss. 1996. "'Who Reasons Well? Two Studies of Informal Reasoning among Children of Different Grade, Ability, and Knowledge Levels." Cognition and Instruction 14 (2): 139-78.

Mehan, Hugh. 1979. “What Time Is It, Denise?”: Asking Known Information Questions in Classroom Discourse." Theory into Practice 18 (4): 285-94.

Mercer, Neil, Rupert Wegerif, and Lyn Dawes. 1999. "Children' s Talk and the Development of Reasoning in the Classroom." British Educational Research Journal 25 (1): 95-111. 
Michaels, Sarah, Catherine O Connor, and Lauren B. Resnick. 2008. "Deliberative Discourse Idealized and Realized: Accountable Talk in the Classroom and in Civic Life," 283-97. https://doi.org/10.1007/s11217-007-9071-1.

Muller-Mirza, Nathalie, and Anne-Nelly Perret-Clermont, eds. 2009. Argumentation and Education: Theoretical Foundations and Practices. New York: Springer.

Nystrand, Martin. 2006. "Research on the Role of Classroom Discourse as It Affects Reading Comprehension." Research in the Teaching of English 40: 392-412.

Perkins, David N., Michael Farady, and Barbara Bushey. 1991. "Everyday Reasoning and the Roots of Intelligence." In Informal Reasoning and Education, 83-105. Mahwah: Lawrence Erlbaum Associates.

Polo, Claire, Kristine Lund, Christian Plantin, and Gerald P Niccolai. 2016. "Group Emotions: The Social and Cognitive Functions of Emotions." International Journal of ComputerSupported Collaborative Learning 11 (2): 123-56.

Rapanta, Chrysi, and Andri Christodoulou. 2019. "Walton's Types of Argumentation Dialogues as Classroom Discourse Sequences." Submitted manuscript.

Schwarz, Baruch, and Michael J. Baker. 2016. Dialogue, Argumentation and Education: History, Theory and Practice. New York: Cambridge University Press.

Scott, Philip H., Eduardo F. Mortimer, and Orlando G. Aguiar. 2006. "The Tension between Authoritative and Dialogic Discourse: A Fundamental Characteristic of Meaning Making Interactions in High School Science Lessons." Science Education 90 (4): 605-31.

Siegel, Harvey. 1985. "Educating Reason: Critical Thinking, Informal Logic, and the Philosophy of Education. Part Two: Philosophical Questions Underlying Education for Critical Thinking." Informal Logic 7 (2\&3): 69-81.

Skidmore, David. 2006. "Pedagogy and Dialogue." Cambridge Journal of Education 36 (4): 503-14. 
Soter, Anna O., Ian A. Wilkinson, P. Karen Murphy, Lucila Rudge, Kristin Reninger, and Margaret Edwards. 2008. "What the Discourse Tells Us: Talk and Indicators of High-Level Comprehension." International Journal of Educational Research 47 (6): 372-91. https://doi.org/10.1016/j.ijer.2009.01.001.

Venville, Grady J, and Vaille M Dawson. 2010. "The Impact of a Classroom Intervention on Grade 10 Students' Argumentation Skills, Informal Reasoning, and Conceptual Understanding of Science." Journal of Research in Science Teaching 47 (8): 95277. https://doi.org/10.1002/tea.20358.

Walton, Douglas. 1989. "Dialogue Theory for Critical Thinking." $\begin{array}{llll}\text { Argumentation } & 3 & \text { (2): } & 169-1884 .\end{array}$ https://doi.org/10.1007/BF00128147.

- 1998. The New Dialectic. Conversational Contexts of Argument. Toronto: University of Toronto Press.

They Are." Informal Logic 30 (2): 159-84.

- 2014. Burden of Proof, Presumption, and Argumentation. New York: Cambridge University Press.

Wegerif, Rupert. 2007. Dialogic, Education and Technology: Expanding the Space of Learning. (Vol. 7). New York: Springer Science \& Business Media.

Weinstein, Mark. 1990. "Towards a Research Agenda for Informal Logic and Critical Thinking." Informal Logic 12 (3): 121-43.

Wells, Gordon, and Rebeca M. Arauz. 2006. "Dialogue in the Classroom." The Journal of the Learning Sciences 15 (3): 379428.

Wenger, Etienne, Richard McDermott, and William Snyder. 2002. Cultivating Communities of Practice. Boston, Massachussets: Harvard Business School Press. 
Wilkinson, Ian A G, Alina Reznitskaya, Kristin Bourdage, Joseph Oyler, Monica Glina, Robert Drewry, Min-Young Kim, and Kathryn Nelson. 2017. "Toward a More Dialogic Pedagogy: Changing Teachers' Beliefs and Practices through Professional Development in Language Arts Classrooms." Language and Education 31(1, SI): 65-82. https://doi.org/10.1080/09500782.2016.1230129.

Zohar, Anat, and Flora Nemet. 2002. "Fostering Students' Knowledge and Argumentation Skills through Dilemmas in Human Genetics." Journal of Research in Science Teaching 39 (1): 35-62. https://doi.org/10.1002/tea.10008. 